\title{
B-chromosomes and male-biased sex ratio with paternal inheritance in the fairy shrimp Branchipus schaefferi (Crustacea, Anostraca)
}

\author{
L Beladjal $^{1}$, TTM Vandekerckhove ${ }^{1,2}$, B Muyssen ${ }^{1}, \mathrm{~J} \mathrm{Heyrman}^{1}$, J de Caesemaeker ${ }^{1}$ and J Mertens ${ }^{1}$ \\ ${ }^{1}$ Laboratorium voor Ecologie (WE11V), Universiteit Gent, K.L. Ledeganckstraat 35, B-9000 Ghent, Belgium; ${ }^{2}$ Laboratorium voor \\ Microbiologie (WE10V), Universiteit Gent, K.L. Ledeganckstraat 35, B-9000 Ghent, Belgium
}

This study reports on male-biased sex ratios in west Mediter-
ranean populations of the freshwater anostracan Branchipus
schaefferi (Crustacea, Anostraca, Branchipodidae), in con-
trast to populations elsewhere. Crossing experiments over
several generations indicate a clear paternal inheritance of
the trait, possibly with a dosage effect. Various mechanisms which may underlie this phenomenon are discussed, the most plausible being the presence of one or more supernumerary ('B') chromosomes - as evidenced by karyological observations - interfering with sex determination and probably having an accumulation mechanism in male individuals. Heredity (2002) 88, 356-360. DOI: 10.1038/sj/hdy/6800061

Keywords: B-chromosomes; sex ratio distortion; paternal inheritance; Branchipus schaefferi; Crustacea, Anostraca

\section{Introduction}

Many animal species include populations composed of unequal numbers of both sexes, a phenomenon known as sex ratio distortion (SRD). SRD may often be under the control of the mother herself, but in many instances sex ratio distorting elements are involved. Sex ratio distorters are a class of selfish genetic elements (Doolittle and Sapienza, 1980; Orgel and Crick, 1980) enhancing their own spread by favouring the transmitting sex. In invertebrates, facultative SRD may result from extrachromosomal influences, especially in female-biased populations infected with maternally inherited cytoplasmic microorganisms (O'Neill et al, 1997, and references cited therein). The latter may feminize or kill embryonic males, enhance host fertility, or induce cytoplasmic incompatibility, male sterility, thelytokous (= mother-todaughter) parthenogenesis or hybrid breakdown. However, in the case of paternally inherited distortion towards the male sex, nuclear transmission of the distorting factor(s) is much more realistic for the mere reason that sperm cell cytoplasm, including extranuclear genes, is largely discarded during spermiogenesis.

Nuclearly transmitted segregation distorters are often associated with B-chromosomes (= Bs, or 'supernumeraries') (Jones and Rees, 1982). Seventy to $80 \%$ of all B-chromosomes gain a higher than Mendelian transmission through preferential segregation into functional gametes at meiosis or by directed non-disjunction during mitosis (Beukeboom, 1994). Accumulation may take place mainly in males (Nur, 1962, 1963; Patton, 1977; Camacho et al, 1980) or in females (Hewitt, 1973; Lucov and Nur,

Correspondence: Dr L Beladjal, Ghent University, Lab. Animal Ecology, K. L. Ledeganckstraat 35, B-9000 Ghent, Belgium.

E-mail: lynda.beladjal@rug.ac.be

Received 29 December 2000; accepted 15 January 2002
1973). When such selfish DNA is transmitted more efficiently or exclusively by males, it may result in the production of male-biased offspring sex ratios.

An extreme example of paternally inherited SRD towards the male sex has been found in Nasonia vitripennis (Hymenoptera: Pteromalidae) populations carrying a B-chromosome called paternal sex ratio (PSR) (Werren et al, 1987; Nur et al, 1988). It occurs in males only and if present, it destroys the paternal chromosome set upon fertilization, rendering the egg haploid with one supernumerary ( $\mathrm{n}$ + PSR). Due to the haplodiploid sex determination system, the initially diploid (female) embryos will thus develop into PSR-carrying males. Quite obviously, PSR will only spread if more than $50 \%$ of the eggs are fertilized (Werren, 1991), a condition observed from maternal sex ratio (MSR) (Skinner, 1982) populations which harbour a cytoplasmic factor causing females to mass-fertilize almost $100 \%$ of their eggs. Driving the host's sex ratio toward $100 \%$ males would be deleterious for PSR in the long term as females become rare (Hamilton, 1967), so counteracting mechanisms against the driving elements often coexist.

A B-chromosome inheritance pattern resembling that of $N$. vitripennis has been found in the flatworm Polycelis nigra (Turbellaria, Tricladida) (Beukeboom et al, 1996). In contrast, a sex ratio effect is lacking due to the animal being hermaphroditic with gynogenetic parthenogenesis; cross-insemination occurs, enabling biparental transmission of the B, whereas the paternally inherited standard chromosomes are always expelled from the fertilized egg.

We discovered paternally inherited SRD towards the male sex in North African and Spanish populations of the diplodiploid fairy shrimp Branchipus schaefferi (Crustacea, Anostraca, Branchipodidae), as opposed to the normal 1:1 sex ratio seen elsewhere in the Mediterranean region. This paper reports on crossing experiments and cyto- 
logical observations suggesting the SRD may be induced by one or more supernumerary chromosomes in males.

\section{Materials and methods}

Most of the experimental work was carried out on one or more of the following three stock populations in culture in our laboratory: (i) Algeria (Boughzoul, Medea), (ii) Spain (Pueblo de Alcolea, Castellón), and (iii) Austria (Neustadt, Wien),

According to Bianchi Bullini et al (1968), B. visnyai has a diploid genome with $2 \mathrm{n}=20$ chromosomes. Since $B$. visnyai is synonymous to $B$. schaefferi (Beladjal and Mertens, 1999; Zarattini et al, 2001), $2 \mathrm{n}=20(\mathrm{n}=10)$ chromosomes are expected to make up the B. schaefferi nucleus. Therefore, 10 males and 10 females from each $B$. schaefferi population were fixed $(5 \mathrm{~min})$ in a freshly made 1:1 mixture of glacial acetic acid and absolute ethanol, wherein the gonads were dissected. Upon rinsing ( $3 \mathrm{~min}$ ) in distilled water, the gonads were transferred to microscope slides and a drop of the DNA-specific fluorescent dye DAPI (4',6-diamidino-2-phenylindole) (1 $\mu \mathrm{g} / \mathrm{ml})$ was added. The preparation was gently squeezed with a cover slip, sealed and viewed under a light microscope (Leitz Laborlux S) equipped with epifluorescence optics in $360 \mathrm{~nm}$ UV. This protocol was also adopted to karyotype different Algerian F1 descendants, the latter either displaying SRD or not. In this way, a correlation could be made between numbers of B-chromosomes and the extent of SRD.

Progeny sex ratios were studied as follows. Starting from resting eggs (cysts) from Algeria, Spain and Austria, laboratory populations were initiated. Upon hatching, nauplii to be used in later crossing experiments were transferred to individual 50-ml containers filled with aerated tap water enriched with unicellular algae (Scenedesmus sp.) as food source (a few drops of a suspension approximately $5 \times 10^{5}$ cells $/ \mathrm{ml}$ ). At sexual maturity they were pair-mated in plastic bottles (20 replicas for F1 crosses) containing 450-ml aerated tap water and algae. The temperature was kept at a constant $25^{\circ} \mathrm{C}\left( \pm 1^{\circ} \mathrm{C}\right)$. Culture vessels were cleaned and food added daily; onethird of the medium was replaced weekly. Cyst production was checked every day and if cysts were present they were harvested with $100-\mu \mathrm{m}$ sieves, dried at $35^{\circ} \mathrm{C}$ and counted to determine the clutch size. A few days later the cysts were artificially hatched in distilled water and virgin adults could be sexed by the end of their first week on the basis of external sexual characters (females have an ovisac and males possess typicallyshaped second antennae). Sex ratios were calculated as $\%$ males.

SRD was assayed by binomial tests based on critical values for proportions by Rohlf and Sokal (1995). Further statistics were carried out with Statistica for Windows (Kernel release 5.5, Statsoft Inc, 2000). The Spearman test was used to address the question of differential female mortality as a hypothetical explanation for male-biased sex ratios. Other important variables such as fecundity, cyst hatchability (or fertility) and longevity were also tested (using the Mann-Whitney U-test) in order to determine their relation to the SRD trait.

Finally, B. schaefferi samples collected from five countries (Algeria, Morocco, Spain, Jordan and Turkey) were checked for sex ratios in the field.

\section{Results}

Chromosome counts of the Algerian SRD B. schaefferi sperm cells clearly showed different haploid conditions: 10 to 13 chromosomes (Figure 1), in contrast to the usual 10. Bianchi Bullini et al (1968) have mentioned that in a $B$. visnyai (a synonym of B. schaefferi) telophase sometimes one or two neatly isolated chromosomes could be seen. These were probably the same supernumeraries as shown in Figure 1. Interestingly, females had no more than 10 chromosomes per haploid set; the same holds true for both sexes from Spain and Austria.

Only the Algerian shrimps showed a biased sex ratio of about 2:1 (mean $63.1 \%$ males). Since the experimental conditions were identical throughout, sex ratio differences could not be ascribed to environmental influences on sex determination. In order to clarify these findings, experimental crosses were set up. Out of 20 parental couples per population, 12 of the Algerian, eight of the Austrian and seven of the Spanish were useful for F1 sex ratio counts (Table 1 ). The remainder produced an insufficient number of cysts. The Algerian F1 sex ratio was approximately 2:1 (pooled $63.7 \%$ overall, ranging from $40.2 \%$ to $99.3 \%$ - see Table 1 for details). None of the Austrian or Spanish populations produced male-biased offspring and the sex ratio was very close to $1: 1 \quad(51.0 \%$ in the Austrian, $49.3 \%$ in the Spanish).

Crosses were extended over several generations. Since the Algerian 9F1 (Table 1) generated a male-biased progeny with an acceptable number of females, it was selected for the following reciprocal crosses (performed in twentyfold) with the non-biased 6F1 (see Table 1) to determine the hereditary pattern of the bias: $\sigma^{1} 9 \mathrm{~F} 1 \times$ ? $9 \mathrm{~F} 1$; o $9 \mathrm{~F} 1 \times$ $6 \mathrm{~F} 1$; o $6 \mathrm{~F} 1 \times 9$ 9F1. As a control for nonbias, we randomly chose ơ 7F1 $\times$ ㅇ $7 \mathrm{~F} 1$, but ơ $6 \mathrm{~F} 1 \times 96 \mathrm{~F} 1$ was also included (as depicted in Figure 2). The results (Table 2) indicate that the high male ratio is strictly paternally inherited, more specifically through some fathers rather than through all males. SRD may range from a mild male preponderance to for example over $90 \%$ males in some of the 9F1 inbreeding crosses and from crossing of $9 \mathrm{~F} 1 \times 96 \mathrm{~F} 1$ crosses. The offspring of the

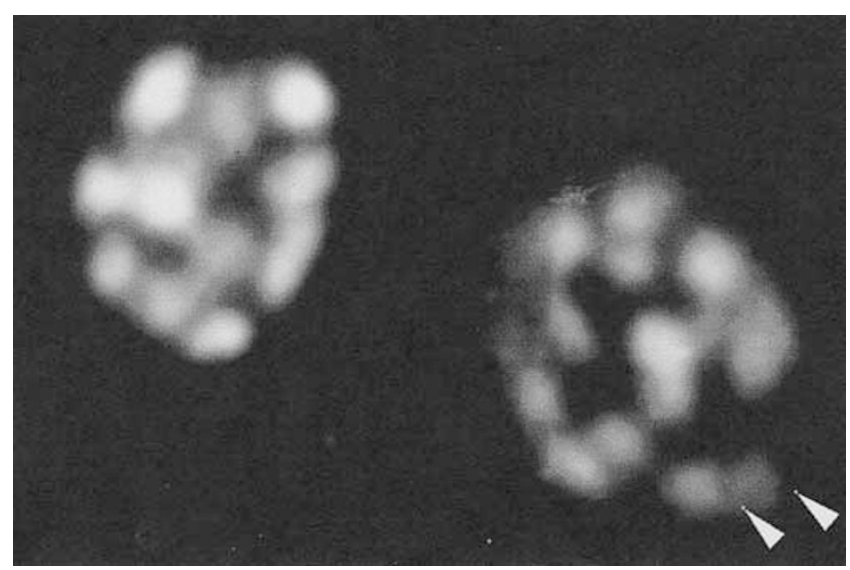

Figure 1 DAPI fluorescence micrograph of chromosomes from Algerian Branchipus schaefferi sperm cells; left, $n=11$ in the haploid set, whereas $n=12$ in the nucleus on the right. Arrowheads point to the latter's two unattached supernumeraries: one very small, the other approximately as large as the smallest A chromosome (= regular, pertaining to the standard $B$. schaefferi genome). 
Table 1 F1 progeny sex ratios ${ }^{a}$ of inbred crosses stemming from cyst populations from three different locations

\begin{tabular}{|c|c|c|c|}
\hline \multirow[t]{2}{*}{ F1 result ${ }^{\mathrm{b}}$} & \multicolumn{3}{|c|}{ Origin of parental population } \\
\hline & Algeria & Austria & Spain \\
\hline $1 \mathrm{~F} 1$ & $40.2(368)^{\mathrm{e}}$ & 46.3 (229) & $46.0(172)$ \\
\hline $2 \mathrm{~F} 1$ & $43.7(261)$ & $46.4(252)$ & $47.8(251)$ \\
\hline $3 \mathrm{~F} 1$ & 48.5 (136) & 50.4 (137) & 48.7 (115) \\
\hline $4 \mathrm{~F} 1$ & $50.3(457)$ & $50.7(67)$ & $49.2(236)$ \\
\hline $5 \mathrm{~F} 1$ & 50.5 (295) & 50.8 (354) & 49.5 (303) \\
\hline $6 \mathrm{~F} 1$ & $53.4(221)$ & $53.0(434)$ & $50.2(309)$ \\
\hline $7 \mathrm{~F} 1$ & $55.8(120)$ & $53.4(487)$ & 50.7 (517) \\
\hline $8 \mathrm{~F} 1$ & $58.9(207)^{\mathrm{d}}$ & $55.7(79)$ & \\
\hline 9F1 & $74.1(224)^{c}$ & & \\
\hline 10F1 & $77.5(435)^{c}$ & & \\
\hline 11F1 & $90.0(440)^{c}$ & & \\
\hline 12F1 & $99.3(292)^{c}$ & & \\
\hline Pooled & $63.7(3456)^{\mathrm{c}}$ & $51.0(2039)$ & 49.3 (1903) \\
\hline Mean & 61.9 & 50.8 & 48.9 \\
\hline
\end{tabular}

axpressed as \% males; total numbers of offspring are given between parentheses; figures in bold face indicate male-biased SR.

${ }^{b}$ Ranked arbitrarily in ascending order of $\%$ males.

'SRD significant at 0.01 level.

dSRD significant at 0.02 level.

eSRD towards female sex significant at 0.01 level. reciprocal cross of $6 \mathrm{~F} 1 \times 99 \mathrm{~F} 1$ had a sex ratio comparable to that of the parental $6 \mathrm{~F}$. Thus a father from a clutch with a high percentage of males has a reasonable chance of producing skewed offspring, whereas a mother from the same clutch has not. Similar results were obtained when the crosses were repeated (surveyed in Figure 2).

Although the karyotyping of Algerian F1 males was preliminary, there are very sound indications that the SRD is indeed tightly associated with the presence of one or more B-chromosomes. For example, the $2 \mathrm{~F} 1$ progeny was not distorted and the single karyotyped male had the standard haploid chromosome number of $n=10$. A 5F1 male, also belonging to a clutch showing no SRD, had $\mathrm{n}=10$ in some cells, but $\mathrm{n}=10+1$ in others. A male from the mildly distorted 9F1 had $\mathrm{n}=10+1$ chromosomes per haploid cell, whereas $\mathrm{n}=10+3$ in the two investigated males from the heavily distorted $12 \mathrm{~F} 1$.

The percentage of males was not significantly correlated with the number of hatched nauplii (Table 3) (Spearman's coefficient of rank correlation, $r s=-0.007, P$ $=0.98)$. Neither was there any significant difference between the SRD (= Algerian) and normal (= either Spanish or Austrian) shrimp populations with respect to fecundity, fertility and longevity (Table 4).

Skew in the field-collected samples was observed in two out of four Algerian populations (Plateau du Fadnoun: 37/42 males, Sidi Makhlouf: 87/126), one out of

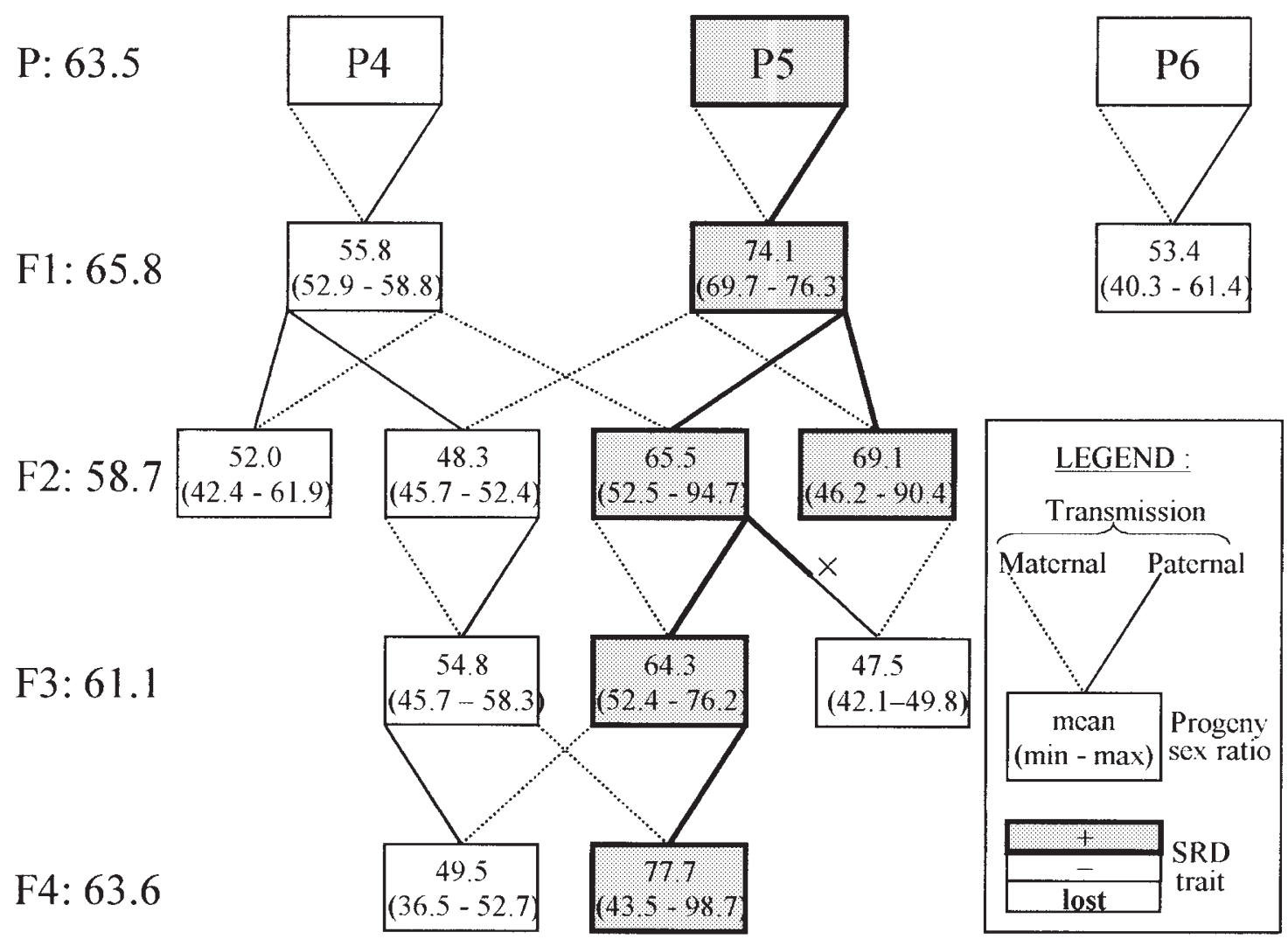

Figure 2 Schematic overview of the exclusive paternal inheritance of SRD observed in Branchipus schaefferi, based on further experimental data from the Algerian laboratory stock. $\times$ denotes loss of the trait. 
Table 2 Algerian F2 progeny sex ratios ${ }^{\mathrm{a}}$ of several crossing types (males written in italics)

\begin{tabular}{|c|c|c|c|c|}
\hline \multirow[t]{2}{*}{ F2 result ${ }^{\mathrm{b}}$} & \multicolumn{4}{|c|}{ Crossing type } \\
\hline & $9 F 1 \times 9 F 1$ & $9 F 1 \times 6 F 1$ & $6 F 1 \times 9 F 1$ & $7 F 1 \times 7 F 1$ \\
\hline 1F1 & 46.2 (117) & $52.5(162)$ & 45.7 (173) & $42.4(66)$ \\
\hline $2 \mathrm{~F} 2$ & 50.5 (95) & 52.9 (206) & $46.3(240)$ & $42.4(59)$ \\
\hline $3 F 2$ & $53.1(81)$ & $53.3(212)$ & 46.6 (116) & $43.2(37)$ \\
\hline $4 \mathrm{~F} 2$ & $64.7(34)$ & 53.8 (145) & 47.7 (197) & $44.2(154)$ \\
\hline $5 \mathrm{~F} 2$ & 66.7 (18) & 57.4 (190) & 48.9 (225) & $48.2(220)$ \\
\hline $6 \mathrm{~F} 2$ & $67.6(37)^{\mathrm{e}}$ & $58.3(72)$ & $51.4(148)$ & 49.3 (144) \\
\hline 7F2 & $71.6(109)^{c}$ & $60.6(66)$ & $52.4(170)$ & $50.0(124)$ \\
\hline $8 \mathrm{~F} 2$ & $74.4(82)^{c}$ & $64.3(28)$ & & 50.4 (113) \\
\hline $9 \mathrm{~F} 2$ & $75.0(20)^{\mathrm{e}}$ & $71.4(224)^{c}$ & & 52.1 (117) \\
\hline 10F2 & $75.0(32)^{\mathrm{c}}$ & $71.9(185)^{c}$ & & $53.8(52)$ \\
\hline 11F2 & $75.9(112)^{c}$ & $80.8(177)^{c}$ & & $55.4(92)$ \\
\hline $12 \mathrm{~F} 2$ & $77.0(148)^{\mathrm{c}}$ & $83.8(68)^{c}$ & & 56.8 (118) \\
\hline 13F2 & $80.0(15)^{\mathrm{e}}$ & $94.7(169)^{c}$ & & $60.2(123)^{\mathrm{e}}$ \\
\hline $14 \mathrm{~F} 2$ & $83.9(93)^{\mathrm{c}}$ & & & $60.3(146)^{\mathrm{d}}$ \\
\hline $15 \mathrm{~F} 2$ & $90.4(73)^{\mathrm{c}}$ & & & $61.9(113)^{\mathrm{d}}$ \\
\hline Pooled & $69.1(1006)^{c}$ & $65.5(1904)^{\mathrm{c}}$ & 48.3 (1269) & $52.0(1678)$ \\
\hline Mean & 70.1 & 65.8 & 48.4 & 51.4 \\
\hline
\end{tabular}

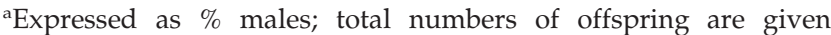
between parentheses; figures in bold face indicate male-biased SR. bRanked arbitrarily in ascending order of $\%$ males.

'SRD significant at 0.01 level.

dSRD significant at 0.02 level.

eSRD significant at 0.05 level.

Table 3 Algerian artificial hatching (as described in the text) and male percentage from a given number of cysts

\begin{tabular}{lrrrr}
\hline Clutch & No. cysts & No. nauplii & $\%$ hatching & $\%$ o' \\
\hline 1 & 2285 & 1386 & 60.66 & 50.2 \\
2 & 1520 & 1136 & 74.74 & 58.5 \\
3 & 1077 & 922 & 85.61 & 99.3 \\
4 & 1587 & 1350 & 85.07 & 92.5 \\
5 & 207 & 197 & 95.17 & 51.2 \\
6 & 291 & 165 & 56.70 & 89.6 \\
7 & 267 & 203 & 76.03 & 52.3 \\
8 & 612 & 441 & 72.06 & 54.5 \\
9 & 590 & 473 & 80.17 & 68.2 \\
10 & 292 & 172 & 58.90 & 63.8 \\
11 & 342 & 227 & 70.06 & 62.8 \\
12 & 488 & 347 & 71.11 & 53.1 \\
13 & 161 & 106 & 65.84 & 60.6 \\
14 & 182 & 120 & 65.93 & 71.9 \\
15 & 238 & 176 & 73.95 & 52.6 \\
Mean & 674.73 & 494.73 & 72.80 & 65.41 \\
\hline
\end{tabular}

Table 4 Mean values ( \pm standard deviation) for life parameters other than sex ratio. All groups consisted of 13 female and 13 male parents. The Mann-Whitney U-test pointed out there were no significant differences between the groups

\begin{tabular}{lccc}
\hline & $\begin{array}{c}\text { Fecundity } \\
(\text { no. of cysts) }\end{array}$ & $\begin{array}{c}\text { Hatchability } \\
\text { of cysts (no.) }\end{array}$ & $\begin{array}{c}\text { Longevity of } \\
\text { parents (days) }\end{array}$ \\
\hline $\begin{array}{l}\text { Algeria (SRD) } \\
\text { Spain (no SRD) }\end{array}$ & $1869( \pm 652)$ & $1153( \pm 413)$ & $35( \pm 10)$ \\
Austria (no SRD) & $2235( \pm 610)$ & $1052( \pm 384)$ & $35( \pm 9)$ \\
\end{tabular}

two Spanish populations (Benicarló: 183/300), and one out of four Moroccan populations (Settat: 67/84), but neither in the Jordanian nor the Turkish stocks, indicating the B. schaefferi SRD trait is limited to the west Mediterranean.

\section{Discussion}

Several causes may underlie the paternal sex ratio phenomenon seen in B. schaefferi: (1) B-chromosome action, (2) differential mortality of females, eg due to a female sex-linked lethal allele, (3) differential female diapausing, and (4) a Y-chromosome with meiotic drive. Let us consider the different options.

B (PSR) transmission and expression were detected in Nasonia by single pair crosses (Werren et al, 1987) between males bearing PSR and standard females, as we found with $B$. schaefferi. Our results show a continual variation in the offspring sex ratio, suggesting it may be determined by several factors (interaction between different allele pairs), or by a variable dosage of one sex factor. In the latter case, a supernumerary chromosome with an accumulation mechanism through spermatogenesis may be a potential candidate. Indeed, a dosage effect may be linked to a variable number of Bs. Moreover, in at least one well-studied example (the New Zealand frog, Leiopelma hochstetteri), sex determination is under control of one single B-chromosome (Green, 1988). However, this does not seem to have an accumulation mechanism and, contrary to $B$. schaefferi, the female is the transmitting sex.

From a parasitologist's viewpoint, the skewed sex ratio in the Algerian B. schaefferi population, if B-chromosome directed, should be seen as an equilibrium between parasite accumulation (ie the transmission drive of selfish DNA, in this case B-chromosomes) and the accompanying negative fitness effects on the host population (Harvey, 1989). The equilibrium sex ratio is seemingly established around $2: 1$ in the laboratory culture but seems to be $4: 1$ in nature. Decreased fitness resulting from B overload may arise through lower viability and/or fecundity, in addition to an increased developmental time in males (Nur, 1966a, b), lower viability in both sexes (Nur, 1977), and/or sperm dysfunction (Hewitt et al, 1987). On the other hand, in B-carrying individuals an increased chiasma formation among autosomes is often observed (John and Hewitt, 1965; Patton, 1977; Camacho et al, 1980), perhaps leading to genetic rearrangements resistant to B-chromosome action (Harvey, 1989). Possible effects on fecundity, fertility (or hatchability of eggs) and longevity associated with SRD in $B$. schaefferi tested negative.

Nonetheless, parameters such as hatchability need careful interpretation in our case since over $90 \%$ of all anostracan cysts enter diapause after deposition. These will hatch to a variable degree if artificially induced to do so by suspending them in distilled water for a few hours. A total eclosion rate of 70-100\% may be reached (Table 3). Considering this, differential female diapause or embryonic lethality can be ruled out as the SRD source in B. schaefferi; otherwise progeny sex ratios over $70 \%$ (the minimum that ecloses) would be impossible.

The fourth possibility, a Y chromosome with meiotic drive as is known for example from mosquitoes (Hickey and Craig, 1966), cannot be entirely excluded. Notwithstanding this, the dosage effect for which preliminary 
indications are apparent from our experiments would then have to be accounted for by a second, variable factor, again suggesting Bs as the driving force.

Figure 2 summarizes the transmission pathways, deduced from crossing experiments as described above spanning five generations, of the unique SRD trait with paternal inheritance of $B$. schaefferi. There is also evidence for the occasional loss of the trait, which could be considered as a natural event counterbalancing SRD and reducing the probability of creating all-male host populations which would soon become extinct.

Further research is now being focused on the dosage effect of the Bs as the most likely force underlying continual variation of SRD in B. schaefferi. If confirmed, this could potentially become an important empirical system.

\section{Acknowledgements}

During the time this work was carried out, TTMV was a Research Assistant of the FWO (Fund for Scientific Research), Flanders, Belgium.

\section{References}

Beladjal L, Mertens J (1999). Direct preservation in alcohol causes deformation of taxonomic key-characters in Anostraca (Crustacea). Int Rev Hydrobio 84: 17-22.

Beukeboom LW (1994). Bewildering Bs: an impression of the 1st B-chromosome conference. Heredity 73: 328-336.

Beukeboom LW, Seif M, Mettenmeyer T, Plowman AB, Michiels NK (1996). Paternal inheritance of B chromosomes in a parthenogenetic hermaphrodite. Heredity 77: 646-654.

Bianchi Bullini A, Bullini L, Cottarelli V (1968). Note sul corredo cromosomico di alcuni Anostraci dulciacquicoli italiani (Crustacea-Euphyllopoda). Lincei Rend Sc fis mat e nat 45: 185-191.

Camacho JPM, Carballo AR, Cabrero J (1980). The B-chromosome system of the grasshopper Eyprepocnemis plorans subsp. plorans (Charpentier). Chromosoma 80: 163-176.

Doolittle WF, Sapienza C (1980). Selfish genes, the phenotype paradigm and genome evolution. Nature 284: 601-603.

Green DM (1988). Cytogenetics of the endemic New Zealand frog, Leiopelma hochstetteri: extraordinary supernumerary chromosome variation and a unique sex chromosome system. Chromosoma 97: 55-70.

Hamilton WD (1967). Extraordinary sex ratios. Science 156: 477-488.

Harvey PH (1989). Parasitological teeth for evolutionary problems. Nature 342: 2300.
Hewitt G (1973). Variable transmission rates of a B-chromosome in Myrmeleotettix maculatus (Thunb.) (Acrididae: Orthoptera). Chromosoma 40: 83-106.

Hewitt GM, East TM, Shaw MW (1987). Sperm dysfunction produced by B-chromosomes in the grasshopper Myrmeleotettix maculatus. Heredity 58: 59-68.

Hickey WA, Craig Jr GB (1966). Genetic distorsion of sex ratio in a mosquito, Aedes Aegypti. Genetics 53: 1177-1196.

John B, Hewitt GM (1965). The B-chromosome system of Myrmeleotettix maculatus (Thunb.) Chromosoma 16: 548-578.

Jones RN, Rees H (1982). B chromosomes. Academic Press: London.

Lucov Z, Nur U (1973). Accumulation of B-chromosomes by preferential segregation in females of the grasshopper $\mathrm{Mel}$ anoplus femur-rubrum. Chromosoma 42: 289-306.

Nur U (1962). A supernumerary chromosome with an accumulation mechanism in the lecanoid genetic system. Chromosoma 13: $249-271$.

Nur U (1963). A mitotically unstable supernumerary chromosome with an accumulation mechanism in a grasshopper. Chromosoma 14: 407-422.

Nur U (1966a). Harmful supernumerary chromosomes in a mealy bug population. Genetics 54: 1225-1238.

Nur U (1966b). The effect of supernumerary chromosomes on the development of mealy bugs. Genetics 54: 1239-1249.

Nur U (1977). Maintenance of a "parasitic" B chromosome in the grasshopper Melanoplus femur-rubrum. Genetics 87: 499512.

Nur U, Werren JH, Eickbush DG, Burke WD, Eickbush TH (1988). A "selfish" B chromosome that enhances its transmission by eliminating the paternal genome. Science 240: 512-514.

O'Neill SL, Hoffmann AA, Werren JH (1997). Influential Passengers. Oxford University Press: Oxford.

Orgel LE, Crick FHC (1980). Selfish DNA: the ultimate parasite. Nature 284: 604-607.

Patton JL (1977). B-chromosome systems in the pocket mouse, Perognathus baileyi: Meiosis and C-band studies. Chromosoma 60: $1-14$.

Rohlf FJ, Sokal RR (1995). Statistical Tables. 3rd edn, Freeman and Compagny: New York.

Skinner SW (1982). Maternally inherited sex ratio in the parasitoid wasp Nasonia vitripennis. Science 215: 1133-1134.

Statsoft (2000). Statistica for Windows. Release 5.5. Statsoft Inc.

Werren JH (1991). The paternal-sex-ratio chromosome of Nasonia. Am Nat 137: 392-402.

Werren JH, Nur U, Eickbush D (1987). An extrachromosomal factor causing loss of paternal chromosomes. Nature 327: 75-76.

Zarattini P, Magnaschi G, Rossi V, Mura G (2001). Further evidence of the synonymy between Branchipus schaefferi and $B$. visnyai (Crustacea, Anostraca). Ital J Zool 68: 79-82. 